\title{
1. Fast and Complete Neutralization of Thiocarbonylthio Compounds Using Trialkylborane and Oxygen: Application to Their Removal ${ }_{3}$ from RAFT-Synthesized Polymers
}

\author{
${ }_{4}$ Prakash Alagi, $^{\dagger}$ Nikos Hadjichristidis, ${ }^{\ddagger 0}$ Yves Gnanou, ${ }^{* \dagger}{ }^{\dagger}$ and Xiaoshuang Feng ${ }^{*}{ }^{\dagger}$ \\ $5{ }^{\dagger}$ Physical Sciences and Engineering Division and ${ }^{*}$ KAUST Catalysis Center, Physical Sciences and Engineering Division, King \\ 6 Abdullah University of Science and Technology (KAUST), Thuwal 23955, Saudi Arabia
}

7 S Supporting Information

8 ABSTRACT: A rapid and efficient method to remove thiocarbo-

9 nylthio end groups from polymers prepared by reversible addition-

10 fragmentation chain transfer (RAFT) is described. The elimination

11 process is obtained in less than $1 \mathrm{~min}$ by treating the solution of

12 RAFT-synthesized polymers with 5 equiv of trialkylborane (TAB) in

13 the presence of oxygen under an ambient temperature. The versatility

14 of this method was checked on the most relevant families of

15 thiocarbonylthio chain transfer agents (CTA), including dithioesters,

16 trithiocarbonates, dithiocarbamates, and xanthates, carried by the

17 corresponding RAFT-synthesized polymers. UV, NMR, and MALDI-

18 TOF MS characterization results all confirm the complete removal of

19 their terminal CTA groups.

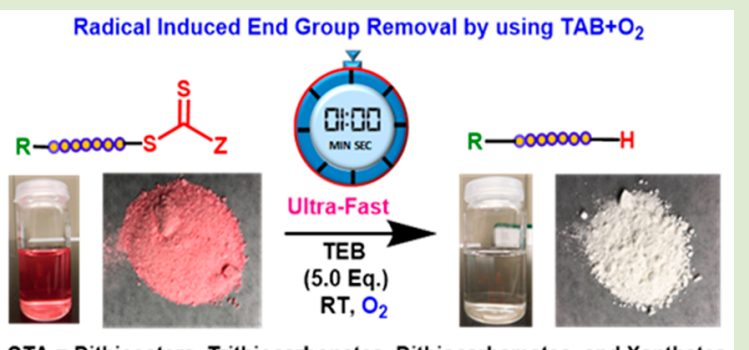

20 eversible addition-fragmentation chain transfer (RAFT) 212 is one of the most versatile controlled/living radical 22 polymerization techniques; ${ }^{1}$ it enables the controlled synthesis 23 of a wide range of homo/copolymers with various function24 alities and architectures. ${ }^{2-4}$ In RAFT polymerizations, the 25 growing macroradical undergoes repeatedly degenerate transfer 26 in the presence of thiocarbonylthio chain transfer agents 27 (CTA), such as dithioesters (DTE), trithiocarbonates (TTC), 28 dithiocarbamates (DTC), and xanthates (XAN), becoming 29 dormant before being active again upon activation by another 30 entering radical. Although these groups are responsible for the 31 controlled/living growth of the chains, their presence in service 32 conditions for commercial applications is often undesirable as 33 they impart to the polymers that carry them their color and 34 toxicity. The elimination of these thiocarbonylthio moieties 35 and their related toxic sulfur residues entails an extra cost that 36 has been in some instances a real obstacle for the 37 commercialization of the RAFT technology. 5,6

38 Several strategies have been considered to remove these 39 sulfur-containing end groups from the RAFT-prepared 40 polymers. $^{7-9}$ As summarized in Scheme 1A, these groups 41 can be displaced by nucleophilic, ${ }^{10-12}$ Diels-Alder, ${ }^{13}$ and 42 radical-induced reactions, ${ }^{14-26}$ as well as by thermolysis. ${ }^{27-30}$ 43 The first two methodologies do not result in the desulfuriza44 tion of the polymer, but in the transformation of the end 45 groups into other sulfur-containing functional groups, which 46 may serve for further reactions. Thermolysis appears to be a 47 powerful method for a complete end-group removal, but it 48 necessitates high temperatures $\left(120-200{ }^{\circ} \mathrm{C}\right)$ and a long time, 49 and it results in unsaturated end groups that may further 50 undergo side reactions. ${ }^{28}$
Radical-induced reactions also provide an effective and 51 complete elimination of the thiocarbonylthio end groups, as 52 detailed in Scheme 1B; the radicals generated from AIBN, ${ }^{15-17} 53$ hydrogen peroxide, ${ }^{23}$ elemental $\mathrm{Fe}$ or $\mathrm{Cu},{ }^{31,32}$ alkoxyamine, ${ }^{19} 54$ or light ${ }^{24-26}$ induce the cleavage of the $\mathrm{C}-\mathrm{S}$ bond upon 55 addition to the thiocarbonylthio end group. In most cases, H- 56 donor additives, such as tributyltin hydride, ${ }^{33}$ tris- 57 (trimethylsilyl)silane, ${ }^{18}$ and $N$-ethylpiperidine hypophos- 58 phite, ${ }^{26}$ had to be added to promote the cleavage reaction 59 and generally require either high temperature or a long 60 reaction time to achieve the end group removal from the 61 RAFT-synthesized polymers.

In this Letter, we unveil a simple, highly efficient, and almost 63 instantaneous procedure to remove the thiocarbonylthio end 64 groups from RAFT-synthesized polymers using trialkylborane 65 (TAB) in open air $\left(\mathrm{O}_{2}\right)$. The method described here (Scheme $66 \mathrm{~s} 2$ 2 ) is actually applicable to all families of RAFT-synthesized $67 \mathrm{~s} 2$ polymers, unlike some of the methods reported before. In fact, 68 $\mathrm{TAB}$ has long been known to be a radical generator in radical 69 polymerization $^{34,35}$ when used in conjunction with $\mathrm{O}_{2}$ : using 70 $\mathrm{TAB} / \mathrm{O}_{2}$ free radicals can be generated at any temperature. 71 Recently Pan, ${ }^{36}$ Magenau, ${ }^{37}$ and their co-workers utilized the 72 $\mathrm{TAB} / \mathrm{O}_{2}$ system to initiate RAFT polymerization. The same 73 $\mathrm{TAB} / \mathrm{O}_{2}$ system is leveraged in this work to neutralize the 74 terminal CTA groups after the completion of RAFT-controlled 75 polymerizations. Our discovery takes advantage of the unique 76 property of $T A B$ to react with $\mathrm{O}_{2}$ and generate very reactive 77

Received: May 15, 2019

Accepted: May 20, 2019 
Scheme 1. Main Reported Processes of RAFT End-Group Removal or Transformation (A), and RAFT End-Group Removal Based on Radical-Induced Reactions (B)

A: End group modification methods

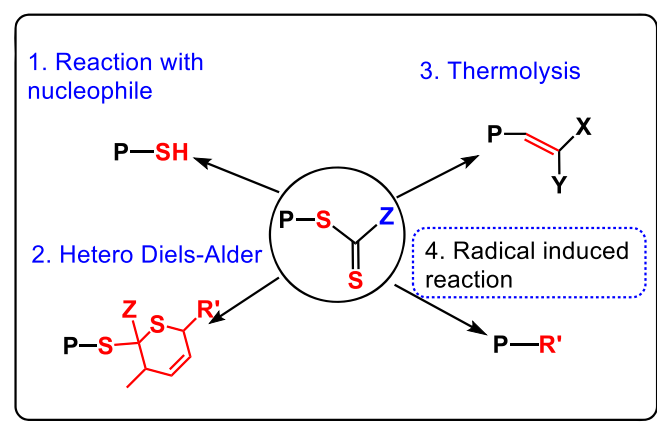

B: Radical induced reactions

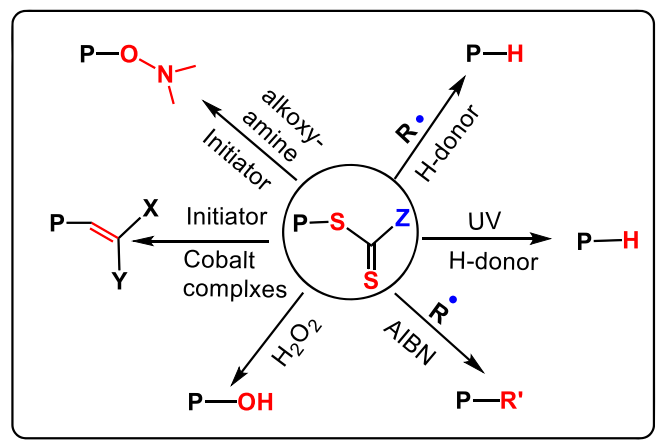

Scheme 2. Synthesis of RAFT Polymers and the Removal of the Respective End Groups from PMMA-DTE, PSTTC $(\mathrm{CN})$, PMA-TTC $\left(\mathrm{CO}_{2} \mathrm{H}\right)$, PVAc-DTC, and PNVP-XAN

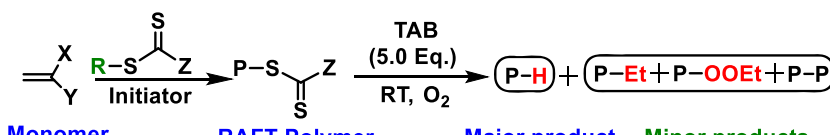

Monomer $\quad$ RAFT Polymer Major product Minor products

CTAs

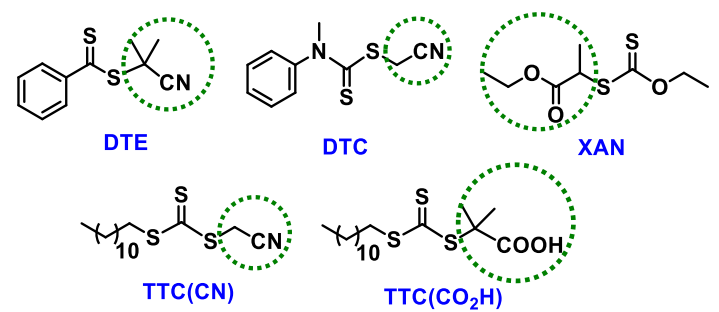

Monomers

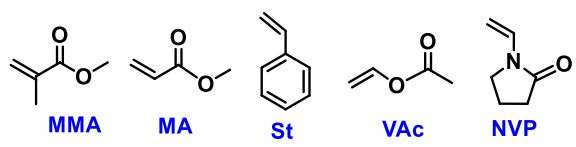

78 alkyl free radicals, which in turn add to the thiocarbonylthio 79 (DTE, TTC, DTC, or XAN) end groups carried by RAFT80 synthesized polymers and remove them from the main chain in 81 just seconds and at room temperature. The simplest TAB, 82 triethylborane (TEB), was first utilized to test the efficiency of 83 end group removal from RAFT-synthesized polymers.

84 PMMA-DTE was first synthesized by RAFT polymerization 85 with 2-cyano-2-propyl benzodithioate as transfer agent and 86 AIBN as radical generator. After completion of the polymer87 ization, 5 equiv of TEB were added into the pink solution of 88 PMMA-DTE in the presence of $\mathrm{O}_{2}$. The strong pink color, 89 typical of the DTE end group, gradually became lighter and totally faded in less than $1 \mathrm{~min}$ (see the video in SI). After 90 precipitation, the white recovered polymer treated by TEB/O $\mathrm{O}_{2} 91$ (denominated as PMMA-T) was submitted to UV-visible, ${ }^{1} \mathrm{H} 92$ NMR, and MALDI-TOF MS characterization. The strong 93 UV-visible signal at $309 \mathrm{~nm}$, due to the DTE group, totally 94 disappeared after treatment, indicating the complete removal 95 of DTE (Figure 1A). The ${ }^{1} \mathrm{H}$ NMR spectra also confirm the $96 \mathrm{fl}$
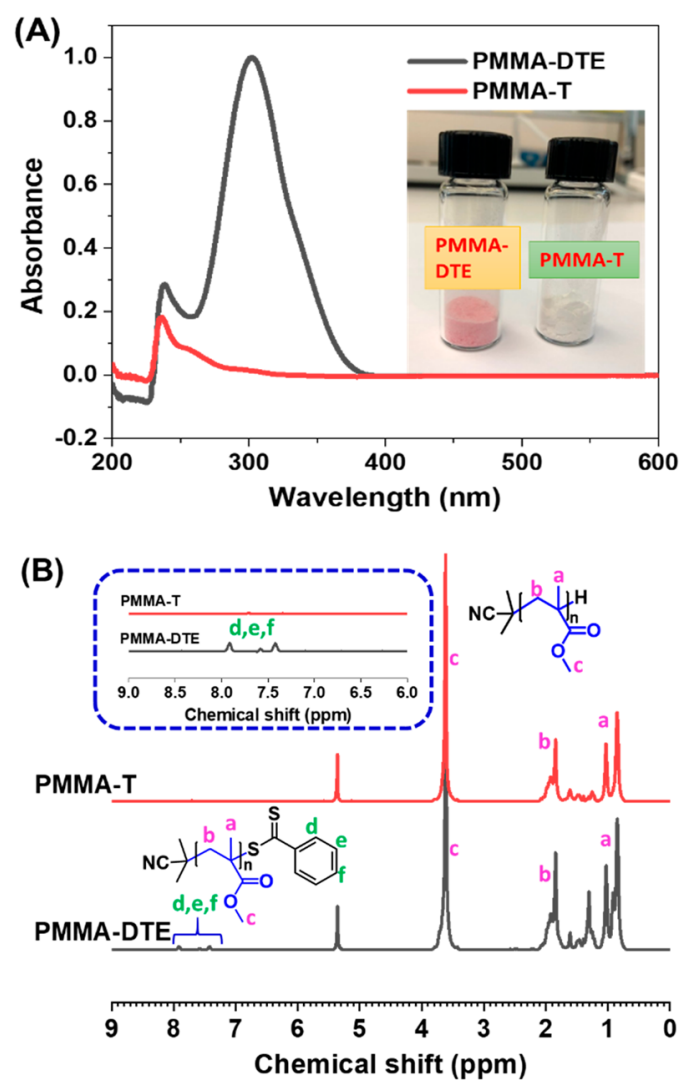

Figure 1. (A) UV-vis absorption spectra and $(B){ }^{1} \mathrm{H}$ NMR spectra of PMMA-DTE before and after treatment with TEB and $\mathrm{O}_{2}$.

disappearance of the terminal DTE group, as no signal due to 97 the aromatic protons could be seen in the spectrum of the 98 PMMA-T sample (Figure 1B), which is consistent with UV 99 spectroscopic results. As for the GPC analysis of PMMA-T, it 100 exhibits exactly the same profile of molar mass and 101 polydispersity as that of the PMMA-DTE precursor (Figure 102 S1A, entry 1, in Table 1). These results suggest that, during the $103 \mathrm{tl}$ $\mathrm{TEB} / \mathrm{O}_{2}$ treatment, the original polymer backbone was 104 untouched and chain-chain couplings did not occur.

To identify the group standing at the chain-end after the 106 $\mathrm{TEB} / \mathrm{O}_{2}$ treatment, PMMA-DTE and PMMA-T were 107 characterized by MALDI-TOF MS mass spectrometry. In the 108 case of PMMA-DTE (Figure 2A), the main population is fitted $109 \mathrm{f} 2$ with a DTE group, and its main peak shows a molar mass of 110 $5047(\mathrm{~m} / z)$ corresponding to $(100.12)_{48}+221.34+23$, where 111 100.12, 221.34, and 23 are the molar mass values of the 112 PMMA monomeric unit, of DTE, and of sodium, respectively. 113 A small population not capped with DTE (PMMA-H) is also 114 detected, with a main peak of molar mass $5096(\mathrm{~m} / \mathrm{z}) 115$ corresponding to the following structure: $(100.12)_{50}+68.10+116$ $1+23$, where 100.12 represents the molar mass of the PMMA 117 monomeric unit, 68.10 is that of 2-cyanoprop-2-yl, 1 being the 118 mass of hydrogen, and 23 is that of the sodium. An incomplete 119 
Table 1. Results of Radical-Induced Reaction of RAFT-Synthesized Polymers with Trialkylborane and $\mathrm{O}_{2}$

\begin{tabular}{|c|c|c|c|c|c|c|c|c|c|}
\hline \multirow[b]{2}{*}{ entry } & \multirow[b]{2}{*}{$\begin{array}{l}\text { RAFT-synthesized } \\
\text { polymer }^{a}\end{array}$} & \multirow[b]{2}{*}[\text{RAFTpolymer}]{$/[\mathrm{TAB}]^{c}$} & \multirow[b]{2}{*}{ solvent } & \multirow[b]{2}{*}{$\underset{\left(\times 10^{3}\right) / \mathrm{PDI}^{b}}{\stackrel{M_{\mathrm{n}}}{ }}$} & \multirow[b]{2}{*}{$\begin{array}{c}M_{\mathrm{n}}\left(\times 10^{3}\right) / \mathrm{PDI} \text { after } \\
\text { treatment }\end{array}$} & \multicolumn{2}{|c|}{$\begin{array}{c}M_{\mathrm{p}}(\text { MALDI- } \\
\text { TOF })\end{array}$} & \multirow[b]{2}{*}{$\begin{array}{l}\text { end group } \\
\text { removal }^{d}\end{array}$} & \multirow[b]{2}{*}{$\begin{array}{l}\text { content of } \\
\mathrm{P}-\mathrm{H}^{e}(\%)\end{array}$} \\
\hline & & & & & & before & after & & \\
\hline 1 & PMMA-DTE & 1:5 (TEB) & THF & $5.2 / 1.18$ & $5.1 / 1.24$ & 5147 & 5095 & complete & 81.0 \\
\hline 2 & PMMA-DTE & 1:5 (TEB) & THF & $26.2 / 1.10$ & $25.5 / 1.17$ & & & complete & \\
\hline 3 & PS-TTC(CN) & 1:5 (TEB) & THF & $3.0 / 1.15$ & $3.4 / 1.25$ & 2941 & $\begin{array}{l}2497 \\
4994\end{array}$ & complete & 13.0 \\
\hline 4 & $\begin{array}{l}\text { PMA- } \\
\text { TTC }\left(\mathrm{CO}_{2} \mathrm{H}\right)\end{array}$ & $1: 5$ (TEB) & THF & $5.4 / 1.14$ & $5.7 / 1.21$ & 4778 & 4415 & complete & 49.7 \\
\hline 5 & PVAc-DTC & 1:5 (TEB) & THF & $5.8 / 1.22$ & $5.9 / 1.26$ & 4292 & 3938 & complete & 78.1 \\
\hline 6 & PNVP-XAN & 1:5 (TEB) & THF & $8.6 / 1.20^{f}$ & $9.2 / 1.24^{f}$ & 2790 & 2789 & complete & 63.3 \\
\hline 7 & PMMA-DTE & 1:5 (TBB) & THF & $5.2 / 1.15$ & $5.1 / 1.22$ & 4653 & 4402 & complete & 34.0 \\
\hline 8 & PMMA-DTE & 1:5 (TiBB) & THF & $5.2 / 1.15$ & $5.2 / 1.18$ & 4845 & 4694 & complete & 45.1 \\
\hline 9 & PMMA-DTE & 1:5 (TEB) & toluene & $5.0 / 1.18$ & $5.3 / 1.21$ & 4652 & 4298 & complete & 51.9 \\
\hline 10 & PMMA-DTE & 1:5 (TEB) & benzene & $5.0 / 1.18$ & $5.3 / 1.20$ & 4652 & 4498 & complete & 52.8 \\
\hline
\end{tabular}

${ }^{a}$ PMMA-DTE: poly(methyl methacrylate) with a dithiobenzoate; PS-TTC $(\mathrm{CN})$ : poly(styrene) with trithiocarbonate; $\mathrm{PMA}-\mathrm{TTC}\left(\mathrm{CO}{ }_{2} \mathrm{H}\right)$ : poly(methyl acrylate) with trithiocarbonate; PVAc-DTC: poly(vinyl acetate) with dithiocarbamate; PNVP-XAN: poly(vinylpyrrolidone) with xanthate. ${ }^{b}$ Determined by GPC using tetrahydrofuran as the eluent and polystyrene as the standard. ${ }^{c}$ The TAB treatment with RAFT polymer were performed at $25{ }^{\circ} \mathrm{C}$ for $1 \mathrm{~min}$. TEB: triethylborane; TBB: tributylborane; TiBB: triisobutylborane. ${ }^{d}$ The extent of end group removal is characterized by ${ }^{1} \mathrm{H}$ NMR, MALDI-TOF MS, and UV-visible spectroscopy. ${ }^{e}$ Estimated by MALDI-TOF MS spectrometry. ${ }^{f}$ Determined by GPC using DMF as the eluent and polystyrene as standard.
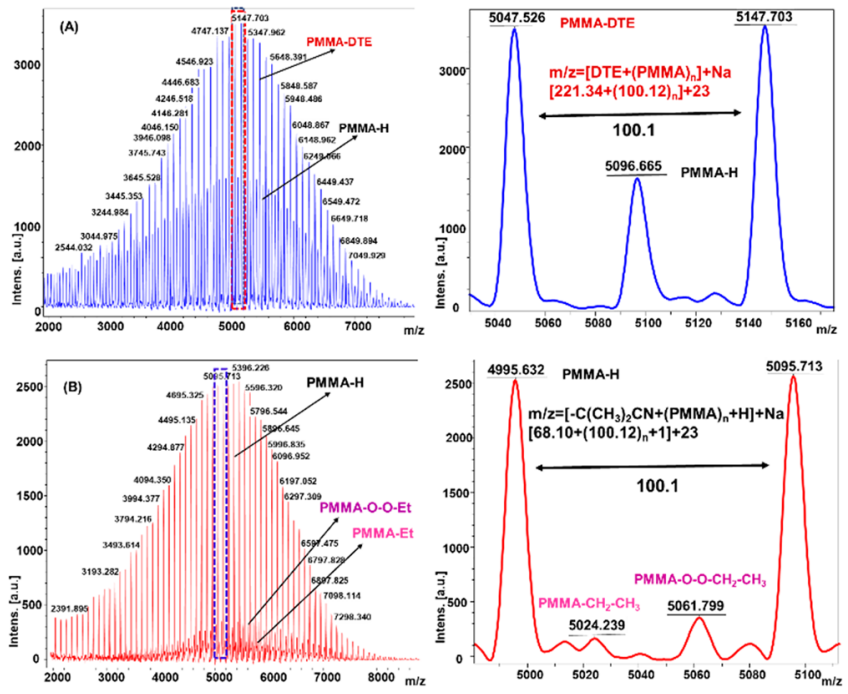

Figure 2. MALDI-TOF MS spectra of RAFT synthesized polymer PMMA-DTE before (A) and PMMA-T after TEB/O $\mathrm{O}_{2}$ treatment (B).

120 functionalization of chains by CTA groups is indeed observed 121 in RAFT polymerization, especially at high conversion. ${ }^{38}$ After $122 \mathrm{TEB} / \mathrm{O}_{2}$ treatment, the MALDI-TOF MS results for the 123 obtained PMMA-T (Figure $2 \mathrm{~B}$ ) showed one main population $\left.124(\mathrm{~m} / z) 4995=(100.12)_{49}+68.10+1+23\right)$, corresponding to 125 PMMA-H terminated with hydrogen. In addition, between the 126 two main repeating signals, two minor populations are 127 detected, corresponding to PMMA- $\mathrm{CH}_{2} \mathrm{CH}_{3}(\mathrm{~m} / z$ 5024), 128 and PMMA-O-O- $\mathrm{CH}_{2}-\mathrm{CH}_{3}(\mathrm{~m} / z$ 5061), respectively. The 129 former population results from the recombination of ethyl 130 radical $\mathrm{Et}^{\bullet}$ with the polymeric radical $\mathrm{PMMA}^{\bullet}$ and the latter 131 one from the recombination of peroxy radical $\mathrm{EtOO}^{\bullet}$ with the 132 polymeric radical $\mathrm{PMMA}^{\bullet}$. It is interesting to stress the 133 absence of any signal at $\mathrm{m} / z 5047$, confirming the complete 134 removal of the terminal DTE group and the transformation of 135 PMMA-DTE into unfunctionalized PMMA. Furthermore, the 136 removal of the end group (DTE) is remarkably reflected on the 137 change of its thermal property. The TGA analysis (Figure S1B) showed an increased thermal stability whose degradation starts 138 only above $180{ }^{\circ} \mathrm{C}$. In contrast, PMMA-DTE exhibits initial 139 degradation at $84{ }^{\circ} \mathrm{C}$, losing up to 15 wt $\%$ at $180{ }^{\circ} \mathrm{C}$. $\quad 140$

After succeeding to remove the DTE group from the RAFT- 141 synthesized PMMA, we prepared four other polymer samples 142 by the RAFT methodology using three different type of CTAs, 143 each of them suited to the monomer to polymerize: 144 polystyrene, poly(methyl acrylate), poly(vinyl acetate), and 145 poly(vinylpyrrolidone) samples were thus derived using 146 TTC $(\mathrm{CN}) \quad[\mathrm{PS}-\mathrm{TTC}(\mathrm{CN})], \quad \mathrm{TTC}\left(\mathrm{CO}_{2} \mathrm{H}\right)$ [PMA-TTC- 147 $\left.\left(\mathrm{CO}_{2} \mathrm{H}\right)\right]$, DTC (PVAc-DTC), and XAN (PNVP-XAN) as 148 RAFT agents (Scheme 2). These different CTAs are indeed 149 reported to allow excellent control of molar mass and to afford 150 samples of narrow polydispersity for these four families of 151 polymers (Table 1). The same reaction conditions, as those 152 described above, were applied to check the versatility of TEB- 153 oxygen based chemistry for chain end removal. In all cases, the 154 color of the solutions submitted to $\mathrm{TEB} / \mathrm{O}_{2}$ treatment 155 disappeared in less than $1 \mathrm{~min}$ as in the PMMA-DTE case 156 after treatment with TEB in the presence of air. All the 157 recovered polymers were respectively characterized by UV, 158 NMR, GPC, MALDI-TOF MS, and the results are 159 summarized in Table 1 . Based on the full characterization 160 data provided in Table S1 and Figures S2-S6, the end terminal 161 CTA groups were totally removed in all cases, and colorless 162 polymers were eventually isolated. Except for PS-T, all samples 163 maintain their original molar mass distributions. 164

In the case of PS-T, a high molar mass bump is indeed seen 165 in the GPC traces (entry 3, Table 1 and Figure S2B), 166 corresponding to the double of the original molar masses 167 which was also detected by MALDI-TOF MS (Figure S6); this 168 is indicative of the occurrence of some polymer-polymer 169 coupling during $\mathrm{TEB} / \mathrm{O}_{2}$ treatment. Indeed, more stable 170 secondary polystyrene radicals are known to undergo such 171 polymer-polymer coupling, unlike tertiary methacrylate 172 radicals. Besides the peak due to PS-PS coupling $\left(\mathrm{m} / z_{173}\right.$ 4994), the MALDI-TOF MS spectrum of PS-T shows three 174 other populations: (1) PS- $\mathrm{CH}_{2} \mathrm{CH}_{3}(\mathrm{~m} / z$ 2913), (2) PS-OO- 175 $\mathrm{CH}_{2} \mathrm{CH}_{3}(m / z$ 2930), and (3) PS-H $(m / z$ 2981), which 176 
177 correspond to (1) the recombination of $\mathrm{Et}^{\bullet}$ radicals with $\mathrm{PS}^{\bullet}$ 178 radicals, (2) the recombination of the peroxy radical with the $179 \mathrm{PS}^{\bullet}$ radical, and (3) the dismutation of $\mathrm{PS}^{\bullet}$ with the above 180 radicals, respectively. In contrast the MALDI-TOF MS 181 spectrum of PS-TTC $(\mathrm{CN})$ exhibited only one single 182 population, the peak at $2941(\mathrm{~m} / z)$ representing the expected 183 PS terminated with TTC $(\mathrm{CN})$ group. As for the MALDI-TOF 184 MS spectrum (Figure S3C) of PMA-TTC $\left(\mathrm{CO}_{2} \mathrm{H}\right)$ prepared 185 with a similar TTC-type transfer agent $-\mathrm{TTC}\left(\mathrm{CO}_{2} \mathrm{H}\right)-$, two 186 main populations corresponding to PMA chains terminated 187 with TTC $\left(\mathrm{CO}_{2} \mathrm{H}\right)\left(\mathrm{m} / z\right.$ 4778, PMA-TTC- $\left.\mathrm{CO}_{2} \mathrm{H}\right)$ and its 188 sodium salt $\left(\mathrm{m} / z\right.$ 4800, PMA-TTC- $\left.\mathrm{CO}_{2} \mathrm{Na}\right)$, along with a 189 minor population of deactivated terminal hydrogen $(\mathrm{m} / z$ 4846, 190 PMA-H) can be seen. After treatment with $\mathrm{TEB} / \mathrm{O}_{2}$, the 191 MALDI-TOF MS spectrum of the obtained PMA-T three 192 populations similar to those of PS-T afforded the following 193 (Figure S3D): $\mathrm{PMA}-\mathrm{CH}_{2} \mathrm{CH}_{3}(\mathrm{~m} / z$ 4788), PMA-OO$194 \mathrm{CH}_{2} \mathrm{CH}_{3}(m / z 4820)$, and PMA-H $(m / z 4845)$. In the case 195 of PVAc-DTC, the MALDI-TOF MS spectrum shows two 196 populations, a major one filled with the DTC end group $(\mathrm{m} / z$ 197 4206, Figure S4C) and a minor one terminated with a $\left(\mathrm{CH}_{3}\right)_{2}$ $198 \mathrm{C}-\mathrm{CN}$ (initiating fragment from AIBN) and $\mathrm{H}$ at two ends $(\mathrm{m} /$ $199 z$ 4139, NC-C $\left(\mathrm{CH}_{3}\right)_{2}$-PVAc-H $)$. After TEB/O $\mathrm{O}_{2}$ treatment, the 200 PVAc- $T$ submitted in MALDI-TOF MS analysis showed one 201 main population confirming the complete removal of the DTC 202 thiocarbonylthio group $(m / z 4197$, PVAc-H, Figure S4D), and 203 one minor population corresponding to the recombination of 204 the polymeric radical PVAc ${ }^{\bullet}$ with the ethyl radical $(\mathrm{m} / z$ 4224, 205 PVAc- $\left.\mathrm{CH}_{2}-\mathrm{CH}_{3}\right)$. Finally, in the case of PNVP-XAN, the 206 MALDI-TOF MS spectrum (Figure S5C) exhibits two main 207 populations corresponding to the following two structures: 208 PNVP-XAN $(m / z 2798)$ and PNVP-H $(m / z 2790)$. After $209 \mathrm{TEB} / \mathrm{O}_{2}$ treatment the MALDI-TOF MS spectrum of resulting 210 polymer showed one major population corresponding to 211 PNVP-H $(m / z$ 2789, Figure S5D) and one small population 212 corresponding to the coupling of the polymeric radical PNVP 213 with ethyl radical: $\mathrm{PNVP}-\mathrm{CH}_{2}-\mathrm{CH}_{3}(\mathrm{~m} / z$ 2819).

214 One additional experiment was carried out with a high molar 215 mass sample PMMA-DTE $(25.5 \mathrm{~kg} / \mathrm{mol}$, entry 2 in Table 1$)$ to 216 check the validity and efficiency of this method of 217 neutralization of thiocarbonylthio end groups over a large 218 spectrum of molar masses. As shown in ${ }^{1} \mathrm{H}$ NMR and UV 219 characterization results DTE group is completely removed 220 from the PMMA sample of $25.5 \mathrm{~kg} / \mathrm{mol}$ (Figure S7).

221 All the cleavage reactions described above were carried out 222 in THF and in the absence of H-donor additives; on the hand $223 \mathrm{THF}$ is known to behave as a $\mathrm{H}$-donor under certain 224 conditions. ${ }^{16}$ Intrigued by the fact that all of our cleavage 225 experiments resulted in the formation of mostly $\mathrm{H}$-terminated 226 chains and to a lesser extent of chains fitted with Et and EtOO 227 moieties, generated by recombination with the corresponding 228 radicals, we tried other TABs than TEB and thus used 229 tributylborane (TBB) and triisobutylborane (TiBB) as cleaving 230 agents in the presence of $\mathrm{O}_{2}$.

231 PMMA-DTE served as a model for this part of the 232 investigation, which was carried out under conditions similar 233 to those used with TEB (entries 7 and 8 in Table 1). 234 Interestingly, the rate of decoloration was even faster than that 235 observed with TEB, following this order: TiBB $>$ TBB $>$ TEB. 236 The complete cleavage and the terminal functionalities after 237 treatment of TiBB and TBB were further characterized by 238 MALDI-TOF MS spectrometry. As shown in Figure S8A,B, in 239 both cases, the major population formed is the H-terminated
PMMA-H, along with two minor PMMA populations resulting 240 from recombination of $\mathrm{PMMA}^{\bullet}$ with $\mathrm{iBu}^{\bullet}$ or $\mathrm{Bu}^{\bullet}$. We then 241 wondered whether the formation of $\mathrm{H}$-terminated PMMA 242 chains could be due to the involvement of THF as H-donor. 243 Two cleavage experiments (entries 9 and 10 in Table 1 ) were 244 thus carried out in benzene ${ }^{27}$ and toluene ${ }^{18,26}$ to check the 245 above hypothesis. As seen in Figure S8C,D, the results 246 obtained were essentially the same as those generated in THF, 247 PMMA-H being by far the major population of cleaved chains. 248

Based on this last result and also the above thorough 249 characterization, especially by MALDI-TOF MS, a straightfor- 250 ward elimination mechanism of CTA using TEB-oxygen is 251 proposed in Scheme 3. In the presence of $\mathrm{O}_{2}$, TEB undergoes $252 \mathrm{~s} 3$

Scheme 3. Plausible Mechanism of RAFT End Group Removal Using TEB and $\mathrm{O}_{2}$

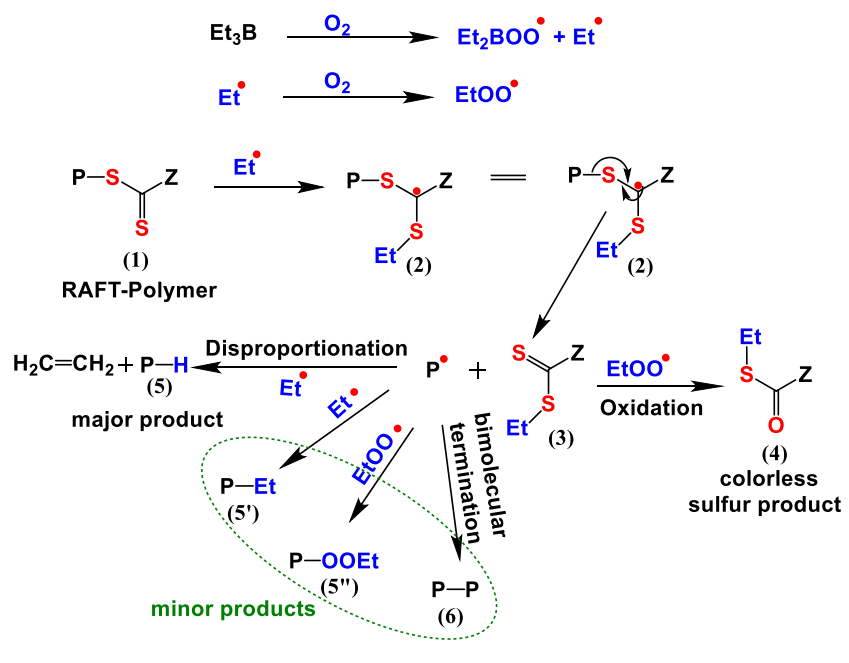

autoxidation and produces an ethyl radical $\left(\mathrm{Et}^{\bullet}\right)$ and boron 253 peroxy radical $\left(\mathrm{Et}_{2} \mathrm{BOO}\right)^{\bullet}{ }^{36,37,39}$ The highly active $\mathrm{Et}^{\bullet}$ radical 254 immediately adds to the $-\mathrm{C}=\mathrm{S}$ bond of the thiocarbonyl 255 group (1) to generate an intermediate that undergoes 256 fragmentation and produces a polymer radical (2) and a new 257 thiocarbonylthio compound (3). Most of these polymeric 258 radicals $\mathrm{P}^{\bullet}$ undergo either disproportionation upon reaction 259 with the $\mathrm{Et}^{\bullet}$ radical to form $\mathrm{P}-\mathrm{H}$ (5) or recombination with 260 $\mathrm{Et}^{\bullet}$ and with the peroxy radical EtOO ${ }^{\bullet}$ to form P-Et $\left(\mathbf{5}^{\prime}\right)$ and 261 P-OOEt $\left(\mathbf{5}^{\prime \prime}\right)$ as minor populations. The role of THF as the 262 $\mathrm{H}$-donor can thus be excluded since very similar results were 263 obtained in benzene and toluene (entries 9 and 10 in Table 1). 264 For clarifying the disproportionation reaction between 265 polymeric radical and ethyl radical, one cleavage experiment 266 was intentionally carried out in a Young's NMR tube to avoid 267 the evolution of any gaseous product. Indeed, as shown in 268 Figure S9, the disproportionation product, ethylene, is 269 unambiguously detected at $5.31 \mathrm{ppm}$ in the mixture of 270 PMMA-DTE treated with TEB/O $\mathrm{O}_{2}$. In the case of PS-CTA, 271 some PS-PS coupling is also observed (6) due to the 272 recombination of two $\mathrm{PS}^{\bullet}$. As for the thiocarbonylthio 273 compound (3) formed upon cleavage from the initial polymer, 274 it undergoes a radical-induced oxidation in the presence of 275 peroxy radical $\mathrm{EtOO}^{\bullet}$, yielding thioesters (4), a colorless stable 276 sulfur compound. ${ }^{40}$ The formation of such thioesters was 277 further confirmed by GC-MS analysis (Figure S10). In this 278 method, the alkyl radicals generated through autoxidation of 279 $\mathrm{TAB}$ first cleave the bond between the polymer and the 280 thiocarbonylthio group, inducing the reaction between the 281 
282 polymeric radicals produced and the continuous flow of $\mathrm{Et}^{\bullet}$ 283 and EtOO $^{\circ}$ radicals. The latter reactions result in either 284 disproportionation or recombination as shown by MALDI285 TOF MS.

286 In attempt to obtain exclusively $\mathrm{H}$-terminated polymers a 287 very similar experiment using PMMA-DTE as model was 288 carried out in the presence of tributyltin hydride, ${ }^{33}$ which is a 289 well-known $\mathrm{H}$-donor additive. As shown in Figure S11, 290 PMMA-H is the sole formed population in contrast to the 291 case where no $\mathrm{H}$-donor was added, which produced a mixture 292 of three populations of PMMA (PMMA-H, PMMA-Et, and 293 PMMA-OOEt).

294 In summary, we established a very simple, fast, and efficient 295 method based on $\mathrm{TAB} / \mathrm{O}_{2}$ for the removal of thiocarbonylthio 296 end groups without altering the polymer carrying such end 297 groups. Thanks to the high reactivity of alkyl radicals produced 298 by autoxidation of $\mathrm{TAB}$, this process can indeed completely 299 knock out all types of CTA end groups from RAFT300 synthesized polymers in seconds and under mild conditions; 301 in the additional presence of $\mathrm{H}$-donors, only $\mathrm{H}$-terminated 302 polymers are produced. We expect that this method, which can 303 be applied after completion of any RAFT polymerization, be it 304 in solution, emulsion, or suspension, will remove the remaining 305 obstacles for the industrial development of this valuable 306 controlled polymerization technique.

\section{ASSOCIATED CONTENT}

\section{S Supporting Information}

309 The Supporting Information is available free of charge on the 310 ACS Publications website at DOI: 10.1021/acsmacro311 lett.9b00357.

312 Experimental details and additional characterization 313 data, including Table S1 and Figures S1-S11 (PDF)

$314 \quad$ Supporting video (MP4)

\section{AUTHOR INFORMATION}

\section{Corresponding Authors}

317 *E-mail: yves.gnanou@kaust.edu.sa.

$318 *$ E-mail: fxs101@gmail.com.

\section{ORCID}

320 Nikos Hadjichristidis: 0000-0003-1442-1714

321 Yves Gnanou: 0000-0001-6253-7856

322 Xiaoshuang Feng: 0000-0001-7473-1728

323 Notes

324 The authors declare no competing financial interest.

\section{ACKNOWLEDGMENTS}

326 This research work is supported by KAUST under baseline 327 funding (BAS/1/1374-01-01).

\section{$328 \square$ REFERENCES}

329 (1) Le, T. P.; Moad, G.; Rizzardo, E.; Thang, S. H. Polymerization 330 with living characteristics with controlled dispersity, polymers 331 prepared thereby, and chain-transfer agents used in the same. WO 3329801478 Al, 1998.

333 (2) Moad, G.; Rizzardo, E.; Thang, S. H. Radical addition334 fragmentation chemistry in polymer synthesis. Polymer 2008, 49, 335 1079-1131.

336 (3) Perrier, S. 50th Anniversary Perspective: RAFT Polymer337 ization-A User Guide. Macromolecules 2017, 50, 7433-7447.
(4) Semsarilar, M.; Perrier, S. "Green" reversible addition- 338 fragmentation chain-transfer (RAFT) polymerization. Nat. Chem. 339 2010, 2, 811.

(5) Destarac, M. Controlled Radical Polymerization: Industrial 341 Stakes, Obstacles and Achievements. Macromol. React. Eng. 2010, 4, 342 165-179.

(6) Destarac, M. Industrial development of reversible-deactivation 344 radical polymerization: is the induction period over? Polym. Chem. 345 2018, 9, 4947.

346

(7) Moad, G.; Rizzardo, E.; Thang, S. H. End-functional polymers, 347 thiocarbonylthio group removal/transformation and reversible 348 addition-fragmentation-chain transfer (RAFT) polymerization. 349 Polym. Int. 2011, 60, 9-25.

(8) Moad, G. A Critical Survey of Dithiocarbamate Reversible 35 Addition-Fragmentation Chain Transfer (RAFT) Agents in Radical 352 Polymerization. J. Polym. Sci., Part A: Polym. Chem. 2019, 57, 216- 353 227.

(9) Willcock, H.; O’Reilly, R. K. End group removal and 355 modification of RAFT polymers. Polym. Chem. 2010, 1, 149-157. 356

(10) Shen, W.; Qiu, Q.; Wang, Y.; Miao, M.; Li, B.; Zhang, T.; Cao, 357 A.; An, Z. Hydrazine as a Nucleophile and Antioxidant for Fast 358 Aminolysis of RAFT Polymers in Air. Macromol. Rapid Commun. 359 2010, 31, 1444-1448.

(11) Qiu, X.-P.; Winnik, F. M. Facile and Efficient One-Pot 361 Transformation of RAFT Polymer End Groups via a Mild 362 Aminolysis/Michael Addition Sequence. Macromol. Rapid Commun. 363 2006, 27, 1648-1653.

364

(12) Xu, J.; He, J.; Fan, D.; Wang, X.; Yang, Y. Aminolysis of 365 Polymers with Thiocarbonylthio Termini Prepared by RAFT 366 Polymerization: The Difference between Polystyrene and Poly- 367 methacrylates. Macromolecules 2006, 39, 8616-8624. 368

(13) Sinnwell, S.; Inglis, A. J.; Davis, T. P.; Stenzel, M. H.; Barner- 369 Kowollik, C. An atom-efficient conjugation approach to well-defined 370 block copolymers using RAFT chemistry and hetero Diels-Alder 371 cycloaddition. Chem. Commun. 2008, 2052-2054. 372

(14) Chen, M.; Ghiggino, K. P.; Smith, T. A.; Thang, S. H.; Wilson, 373 G. J. Mechanisms of Excimer Formation in Poly(acenaphthylene). 374 Aust. J. Chem. 2004, 57, 1175-1177. 375

(15) Chen, M.; Moad, G.; Rizzardo, E. Thiocarbonylthio end group 376 removal from RAFT-synthesized polymers by a radical-induced 377 process. J. Polym. Sci., Part A: Polym. Chem. 2009, 47, 6704-6714. 378 (16) Gruendling, T.; Dietrich, M.; Barner-Kowollik, C. A Novel 379 One-Pot Procedure for the Fast and Efficient Conversion of RAFT 380 Polymers into Hydroxy-Functional Polymers. Aust. J. Chem. 2009, 62, 381 806-812.

382

(17) Perrier, S.; Takolpuckdee, P.; Mars, C. A. Reversible Addition- 383 Fragmentation Chain Transfer Polymerization: End Group Mod- 384 ification for Functionalized Polymers and Chain Transfer Agent 385 Recovery. Macromolecules 2005, 38, 2033-2036.

(18) Chong, Y. K.; Moad, G.; Rizzardo, E.; Thang, S. H. 387 Thiocarbonylthio End Group Removal from RAFT-Synthesized 388 Polymers by Radical-Induced Reduction. Macromolecules 2007, 40, 389 4446-4455.

390

(19) Favier, A.; Luneau, B.; Vinas, J.; Laïssaoui, N.; Gigmes, D.; 391 Bertin, D. Exchange of Substituents between (Macro)Alkoxyamines 392 and (Macro)RAFT Agents (ESARA): A Bridge between Nitroxide- 393 Mediated and RAFT Controlled Radical Polymerization Techniques. 394 Macromolecules 2009, 42, 5953-5964.

(20) Hornung, C. H.; Postma, A.; Saubern, S.; Chiefari, J. A 396 Continuous Flow Process for the Radical Induced End Group 397 Removal of RAFT Polymers. Macromol. React. Eng. 2012, 6, 246-251. 398 (21) Soeriyadi, A. H.; Boyer, C.; Burns, J.; Becer, C. R.; Whittaker, 399 M. R.; Haddleton, D. M.; Davis, T. P. High fidelity vinyl terminated 400 polymers by combining RAFT and cobalt catalytic chain transfer 401 (CCT) polymerization methods. Chem. Commun. 2010, 46, 6338- 402 6340.

403

(22) Matioszek, D.; Dufils, P.-E.; Vinas, J.; Destarac, M. Selective 404 and Quantitative Oxidation of Xanthate End-Groups of RAFT 405 
406 Poly(n-butyl acrylate) Latexes by Ozonolysis. Macromol. Rapid 407 Commun. 2015, 36, 1354-1361.

408 (23) Jesson, C. P.; Pearce, C. M.; Simon, H.; Werner, A.; 409 Cunningham, V. J.; Lovett, J. R.; Smallridge, M. J.; Warren, N. J.; 410 Armes, S. P. H2O2 Enables Convenient Removal of RAFT End411 Groups from Block Copolymer Nano-Objects Prepared via Polymer412 ization-Induced Self-Assembly in Water. Macromolecules 2017, 50, $413 \quad 182-191$.

414 (24) Mattson, K. M.; Pester, C. W.; Gutekunst, W. R.; Hsueh, A. T.; 415 Discekici, E. H.; Luo, Y.; Schmidt, B. V. K. J.; McGrath, A. J.; Clark, P. 416 G.; Hawker, C. J. Metal-Free Removal of Polymer Chain Ends Using 417 Light. Macromolecules 2016, 49, 8162-8166.

418 (25) Discekici, E. H.; Shankel, S. L.; Anastasaki, A.; Oschmann, B.; 419 Lee, I.-H.; Niu, J.; McGrath, A. J.; Clark, P. G.; Laitar, D. S.; de Alaniz, 420 J. R.; Hawker, C. J.; Lunn, D. J. Dual-pathway chain-end modification 421 of RAFT polymers using visible light and metal-free conditions. Chem. 422 Commun. 2017, 53, 1888-1891.

423 (26) Carmean, R. N.; Figg, C. A.; Scheutz, G. M.; Kubo, T.; 424 Sumerlin, B. S. Catalyst-Free Photoinduced End-Group Removal of 425 Thiocarbonylthio Functionality. ACS Macro Lett. 2017, 6, 185-189. 426 (27) Postma, A.; Davis, T. P.; Li, G.; Moad, G.; O'Shea, M. S. RAFT 427 Polymerization with Phthalimidomethyl Trithiocarbonates or Xan428 thates. On the Origin of Bimodal Molecular Weight Distributions in 429 Living Radical Polymerization. Macromolecules 2006, 39, 5307-5318. 430 (28) Postma, A.; Davis, T. P.; Moad, G.; O’Shea, M. S. Thermolysis 431 of RAFT-Synthesized Polymers. A Convenient Method for 432 Trithiocarbonate Group Elimination. Macromolecules 2005, 38, $4335371-5374$.

434 (29) Xu, J.; He, J.; Fan, D.; Tang, W.; Yang, Y. Thermal 435 Decomposition of Dithioesters and Its Effect on RAFT Polymer436 ization. Macromolecules 2006, 39, 3753-3759.

437 (30) Zhou, Y.; He, J.; Li, C.; Hong, L.; Yang, Y. Dependence of 438 Thermal Stability on Molecular Structure of RAFT/MADIX Agents: 439 A Kinetic and Mechanistic Study. Macromolecules 2011, 44, 84464408457.

441 (31) Zhang, X.; Wang, W.; Guo, K.; Wesdemiotis, C.; Zhang, Z.; $442 \mathrm{Zhu}, \mathrm{X}$. Zero-valent metal catalyzed radical-induced adjustable $443 \mathrm{removal} /$ modification of thiocarbonylthio end groups of RAFT 444 polymer at ambient temperature. Polym. Chem. 2013, 4, 637-644.

445 (32) Wu, Y.; Zhao, J.; Zhang, X.; Zhu, J.; Zhang, W.; Zhang, Z.; Zhu, $446 \mathrm{X}$. Zero-valent metal catalyzed removal of thiocarbonylthio end 447 groups from RAFT-made polystyrene: producing controllable 448 bimodal molecular weight distribution. Polym. Chem. 2014, 5, 449 1992-1998.

450 (33) Chen, M.; Ghiggino, K. P.; Thang, S. H.; White, J.; Wilson, G. $451 \mathrm{~J}$. Synthesis and Fluorescence of a Series of Multichromophoric 452 Acenaphthenyl Compounds. J. Org. Chem. 2005, 70, 1844-1852. 453 (34) Furukawa, J.; Tsuruta, T.; Inoue, S. Triethylboron as an 454 initiator for vinyl polymerization. J. Polym. Sci. 1957, 26, 234-236.

455 (35) Welch, F. J. Polymerization of methyl methacrylate by 456 triethylboron-oxygen mixtures. J. Polym. Sci. 1962, 61, 243-252.

457 (36) Lv, C.; He, C.; Pan, X. Oxygen-Initiated and Regulated 458 Controlled Radical Polymerization under Ambient Conditions. 459 Angew. Chem., Int. Ed. 2018, 57, 9430-9433.

460 (37) Wilson, O. R.; Magenau, A. J. D. Oxygen Tolerant and Room 461 Temperature RAFT through Alkylborane Initiation. ACS Macro Lett. 462 2018, 7, 370-375.

463 (38) Chong, Y. K.; Le, T. P. T.; Moad, G.; Rizzardo, E.; Thang, S. H. 464 A more versatile route to block copolymers and other polymers of 465 complex architecture by living radical polymerization: the RAFT 466 process. Macromolecules 1999, 32, 2071-2074.

467 (39) Zhang, Z.-C.; Chung, T. C. M. Reaction Mechanism of 468 Borane/Oxygen Radical Initiators during the Polymerization of 469 Fluoromonomers. Macromolecules 2006, 39, 5187-5189.

470 (40) Li, C.; He, J.; Zhou, Y.; Gu, Y.; Yang, Y. Radical-induced 471 oxidation of RAFT agents-A kinetic study. J. Polym. Sci., Part A: 472 Polym. Chem. 2011, 49, 1351-1360. 